\title{
Block copolymer membranes
}

\author{
Suzana P. Nunes \\ King Abdullah University of Science and Technology (KAUST), \\ Biological and Environmental Science and Engineering (BESE), \\ 23955-6900 Thuwal, Saudi Arabia
}

Block copolymers have naturally attracted the interest of membrane scientists for decades. The main reasons for that are the versatility of morphologies and the possibility of precisely tuning them at the nanoscale level and combining materials with different properties in one single membrane. Ideally, by choosing the right segments and the proper membrane fabrication process, block copolymers could add advantages for various applications. Here the state-of-the-art and perspectives in the field of block copolymer membranes will be summarized and critically discussed.

\section{Block copolymer equilibrium morphology}

Block copolymers have a rich and well-defined morphology in the melt, guided by the interaction between different blocks. Excellent reviews on the block copolymer self-assembly in the solid state have been published by Bates et al. [1-3], discussing in detail the morphology as a function of the block-block Flory-Huggins thermodynamic interaction parameter, $\chi_{\mathrm{AB}}$, the degree of polymerization, $N$, and the size fraction of each block $f_{\mathrm{A}}=N_{\mathrm{A}} / N$. For the self-assembly to take place and lead to an ordered arrangement as spheres, cylinders or lamellae, a minimum value of $\chi_{\mathrm{AB}} \mathrm{N}<10.5$, as shown in Figure 1. For block copolymer dense films or porous membranes prepared by sacrificial etching of one of the blocks after the self-assembly, the order-disorder phase diagram is fundamental. These are equilibrium or metastable morphologies, and their prediction is valid only for systems enabled to anneal long enough to delete any history of solvent influence or non-equilibrium condition.

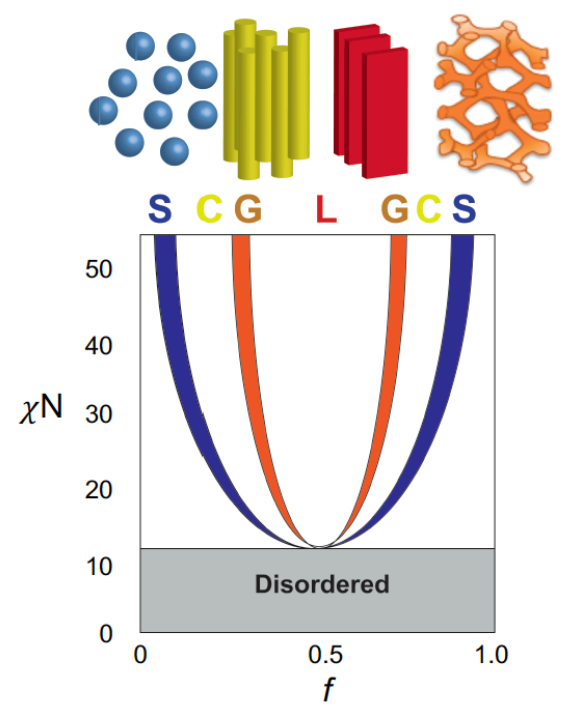

Figure 1. Diblock copolymer morphology in the melt: spheres, cylinders, lamellae, gyroid.[1] 
The polymeric membrane manufacture mostly includes a step of solution casting. The selfassembly of block copolymers in solution leads to an ordered morphology, which depends not only on the interaction between block but also the interaction between each block and the solvents and copolymer concentration. The large variety of morphologies of block copolymers in solution could be explained and roughly predicted by using the simplified concept of packing factors, proposed for surfactants, as in Figure 2.[4]

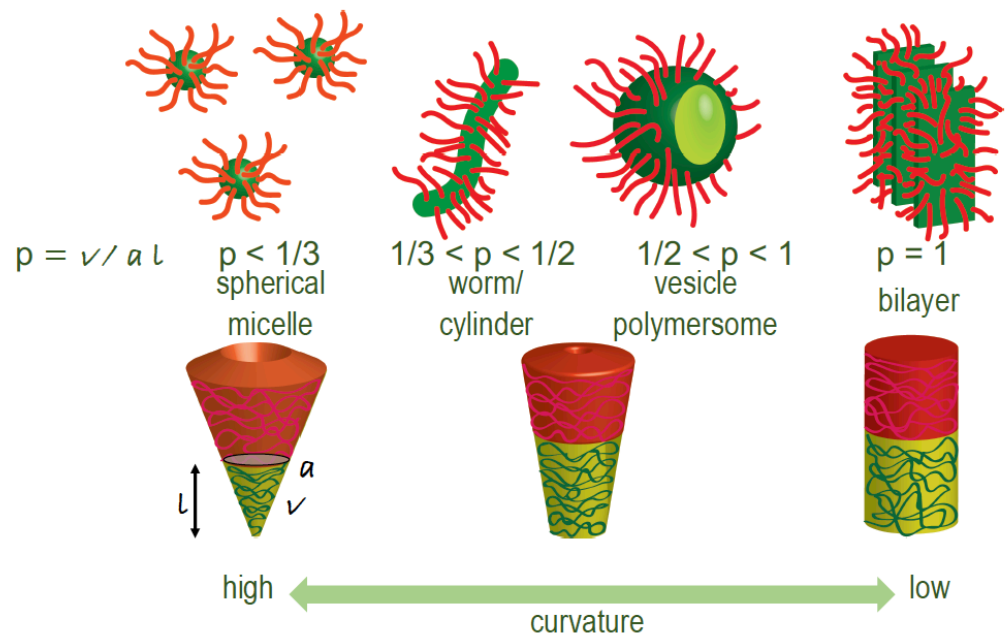

Figure 2. Diblock copolymer morphologies in solution.[4, 5]

Dense membranes for gas, vapor and liquid separation, and proton conduction

The most explored block copolymers for membrane fabrication are those commercialized as Pebax ${ }^{\circledR}$ by Arkema, and Nexar ${ }^{\mathrm{TM}}$, by Kraton (Scheme 1). Pebax ${ }^{\circledR}$ is a polyether- $b$-polyamide copolymer with different degrees of hydrophilicity. Due to its excellent balance of transport properties, limited swelling, and mechanical stability, Nexar ${ }^{\mathrm{TM}}$ has been explored for different membrane applications, such as gas separation[6], ultra- and nanofiltration[7, 8], pervaporation.[9] Pebax ${ }^{\circledR}$ is hardly soluble in single solvents due to the polyamide block and this delayed its use for membrane manufacture. The first reports[6] dissolved Pebax ${ }^{\circledR}$ in n-butanol or 1,1,2trichloroethane by heating close to the solvent boiling point. Solvent mixtures are in many cases successful in dissolving block copolymers in concentrations useful for membrane preparation and water/ethanol was later successfully applied as a convenient solvent for the hydrophilic Pebax ${ }^{\circledR}$ grade.[10] Pebax ${ }^{\circledR}$ polyether blocks strongly interacts with $\mathrm{CO}_{2}$, while the polyamide block hinders an excessive plasticization and swelling, which otherwise would reduce the selectivity in real operation. This approach has secured $\mathrm{CO}_{2}$ permeability of 73 Barrer for the pure copolymers and $\mathrm{CO}_{2} / \mathrm{N}_{2}$ and $\mathrm{CO}_{2} / \mathrm{CH}_{4}$ selectivity values[11] of 15.6 , suitable for industrial applications.[12, 13] By adding poly(ethylene glycol)[11] or other components such as ionic liquids[14], oligomers of ionic liquid-silica[10] and metal-organic frameworks[ $[15,16]$ dispersed in the polyether phase, the permeability could increase above 150 Barrer. Polyactive ${ }^{\mathrm{TM}}$ is a commercial copolymer with 
poly(butylene terephthalate) block instead of polyamide, which also have excellent permeation and selectivity characteristics for $\mathrm{CO}_{2}$ separations.[17] Beside $\mathrm{CO}_{2}$ other acid gases such as $\mathrm{H}_{2} \mathrm{~S}$ and $\mathrm{SO}_{2}$ have a preferential permeation through $\mathrm{Pebax}^{\circledR} \cdot[18]$

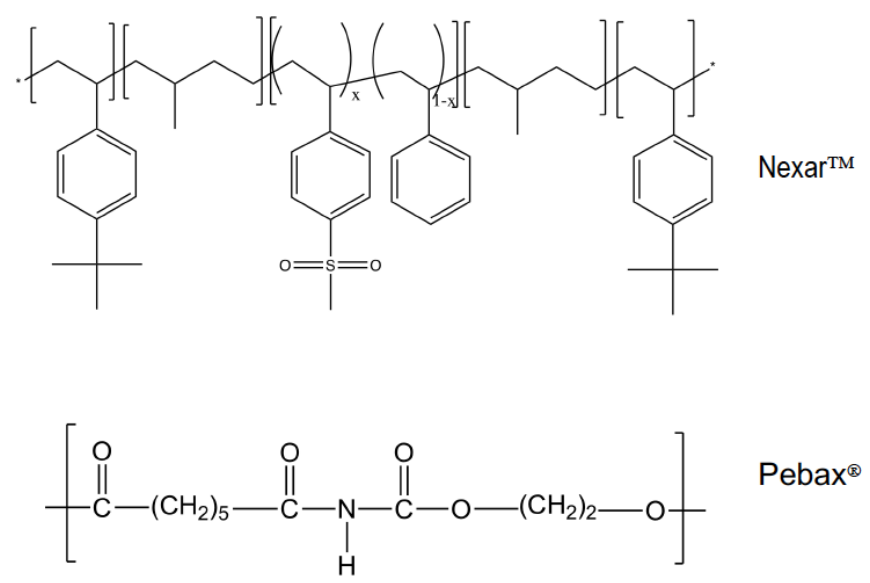

Scheme 1. Commercial block copolymers Nexar ${ }^{\mathrm{TM}}$ and Pebax ${ }^{\circledR}$

The availability of Pebax ${ }^{\circledR}$ (Scheme 1) in hydrophilic and hydrophobic grades facilitates its application for dehydration and removal of organic compounds by pervaporation, demonstrated decades ago.[9, 19-21] The nanostructuration, high hydrophilicity and controlled swelling of Pebax ${ }^{\circledR}$ has been responsible for the successful performance of dense ultrafiltration membranes[8], for which separation does not rely on well-defined pore size, but rather on a combination of solution-diffusion mechanism favored by the water polyether affinity, high flexibility of the hydrophilic segments linked by insoluble polyamide domains. The hydrophilicity also helps in decreasing the fouling susceptibility. Crosslinking strategies and the incorporation of fillers, and inorganic phases could decrease the molecular weight cut off or these membranes for application in nanofiltration in aqueous and organic medium or in bioelectrochemical devices.[7, 22, 23]

$\mathrm{Nexar}^{\mathrm{TM}}$ (Scheme 1) is a pentablock of tert-styrene, hydrogenated isoprene, and randomly sulfonated styrene. The copolymer has been mainly explored for the preparation of dense layers on porous supports for different membrane applications. Geise et al.[24] were the first to report on Nexar ${ }^{\mathrm{TM}}$ application as a membrane, investigating it for desalination. Thong et al.[25] demonstrated the application of Nexar ${ }^{\mathrm{TM}}$ nanofiltration membranes for removing heavy metal ions from wastewater with water permeation of $2.4 \mathrm{~L} \mathrm{~m}^{-2} \mathrm{~h}^{-1} \mathrm{bar}^{-1}$. The membrane was prepared using a polyethyleneimine gutter layer between a porous support and the copolymer layer. The reported solute rejection corresponds to that of a membrane with $0.5 \mathrm{~nm}$ "pore" diameter, however, like for Pebax ${ }^{\circledR}$ nanofiltration membranes, a simple size-sieving in this separation range is not necessarily the dominant acting transport mechanism.[26] Nexar ${ }^{\mathrm{TM}}$ was used for alcohol dehydration via pervaporation as a single layer[27] or as the polyanion in a layer-by-layer membrane on hydrolyzed polyacrylonitrile.[28] The morphology is important. The cyclic hydration of Nexar ${ }^{\mathrm{TM}}$ films promotes a transition to a more interconnected network of sulfonated domains[29] that favors the water transport. By choosing the right solvents to cast Nexar ${ }^{\mathrm{TM}}$ films, the water transport can be several times increased.[30] 
Due to the sulfonated blocks of Nexar ${ }^{\mathrm{TM}}$, it has been considered for proton transport, required for a fuel cell, vanadium flow battery or ionomer actuators.[31] As for water transport, the morphology is very important for the proton transport. Although this can be controlled, the stability under oxidative conditions is also mandatory for fuel cell applications.

The synthesis and testing of cation-exchange copolymer membranes with protons conductive blocks for fuel cell have been proposed by Taeger et al.[32] as sulfonated aramides, and Alvarez-Gallego et al.[33] as sulfonated polynaphthalimides with benzimidazole pendant groups. The influence of the morphology on proton conductive membranes based on block copolymers, as well as for application in lithium and redox flow batteries, actuators and electrodialysis, has been revised by Shin et al.. [34] More recent developments based on fluorinated block copolymers for anion exchange membranes with high free volume for hydroxide ion transport have been reported.[35]

\section{Surface modification for water-based separations}

The membrane surface functionalization with poly (ethylene glycol) (PEG) or zwitterionic segments is a common strategy to minimize fouling during the filtration of aqueous streams. McCloskey et al. [36] adopted a polydopamine coating layer as a platform for further functionalization and incorporation of PEG segments on membrane surfaces. This grafting strategy has been later used by many groups leading to covalently bonded hydrophilic segments.[37, 38] An interesting approach for membrane modification was proposed by Xie et al.[39]. Membranes were prepared from copolymers of plain polysulfone and azidomethylated polysulfone. A postfunctionalization by click reaction with propargyl alcohol attached hydrophilic 1,2,3-triazole groups to the membrane. The click reaction strategy could be in principle used for a large variety of polymers and copolymer membranes. Instead of grafting or post-functionalization, linear block copolymers can be used as additives. In this case, the hydrophilic segment is normally distributed on the surface, while the second block strongly interacts with the membrane, physically anchoring the chain to the surface. A recent example is the use of poly(ethylene oxide)- $b$-poly (methyl methacrylate) as additive for poly(vinylidene fluoride) (PVDF) ultrafiltration membranes.[40] Poly (methyl methacrylate) and PVDF are miscible and have been previously used as homopolymer blend for membrane preparation.[41] When the block copolymer is used, the acrylate segment is miscible with the PVDF matrix, but the poly(ethylene oxide) block tend to migrate to the membrane-water interface.

The nanostructuration of alternating hydrophobic and hydrophilic groups is believed to be even more effective in mitigating fouling. Self-assembled copolymers with PEG and fluoroblocks are proposed as fouling release coatings.[42-45] Oligomeric zwitterionic building blocks have been recently integrated into an interfacially polymerized polyamide membrane with successful increase of fouling resistance.[46] More recently copolymers containing peptides blocks are being explored as anti-fouling coatings. Zwitterionic peptides[47] or zwitterionic block copolymers based on glutamic acid and lysine[48] have been recently reported for this purpose.

\section{Porous ultra-, nanofiltration membranes and biomimetic $3 D$ structures}

The variety of morphologies that can be achieved with block copolymer has attracted the imagination of membrane scientists for long and different approaches have been tested. They could 
be summarized as two main strategies: (1) the preparation of dense films, followed by etching or partial solubilization and (2) self-assembly and non-solvent phase separation (SNIPS).

\section{Etching of dense films}

The pioneer approaches on porous block copolymer membranes were based on a selective etching of one of the blocks, for instance by exposing polyisoprene- $b$-poly(4-vinylphenyldimethyl-2-propoxysilane) or polystyrene-b-polyisoprene copolymers to ozone. The ozonolysis etches out the isoprene blocks.[49-51] Plasma etching, reactive ion etching, and UV-induced degradation are other applied strategies, besides ozonolysis.[52-54] The sacrifice of poly(lactic acid) (PLA) blocks, by etching with alkaline solutions, have been explored in different ways by the Hillmyer's group. [55-59] The etching has been recently applied to membranes prepared from copolymers with robust norbornene blocks bearing amines and side chains of polylactide and liquid crystal forming blocks.[60] Particularly interesting approaches were proposed, combining a polymerization-induced phase separation and in situ block copolymer formation, as well as crosslinking strategies, followed by selective etching of segments to form pores.[59, 61, 62] The combination of block copolymer self-assembly, interfacial polymerization and selective etching is also a promising approach.[58] The main focus of this review is however the block copolymer membranes prepared by non-solvent induced phase separation as discussed below.

\section{Self-assembly and non-solvent induced phase separation (SNIPS)}

First reports and basic principles. The combination of block copolymer self-assembly and process, leading to an isoporous membrane without an etching step or selective dissolution of a pore forming additive, was first prepared by Peinemann in the frame of the European project COMPOSE-Multicomponent nanostructured materials for separation membranes (2004-2007) and reported as Peinemann et al. [63]. The process consists of casting a copolymer solution, followed by a short partial solvent evaporation and immersion in a non-solvent, normally water, and is represented in Figure 3. Peinemann[63] worked with polystyrene- $b$-poly(4vinyl pyridine) (PS- $b$ P4VP) (Scheme 2) and chose the same optimized conditions and solvents he previously used for the preparation of polyimide dense asymmetric membranes, using a mixture of dimethylformamide (DMF) and tetrahydrofuran (THF) as solvent. The obtained structure was fascinating. However, it could initially be hardly reproduced with other batches of the same copolymer at that time. Only years later, [64] after a better understanding of the formation mechanism and the influence of the copolymer self-assembly, forming micelles that themselves assume a regular order already in the casting solution, isoporous membranes could be properly reproduced and explored in different approached. Since these initial reports, SNIPS is developing as a membrane field itself investigated by different groups. Figure 4 shows a typical example of isoporous membrane surface morphology, imaged by scanning electron microscopy (SEM). 


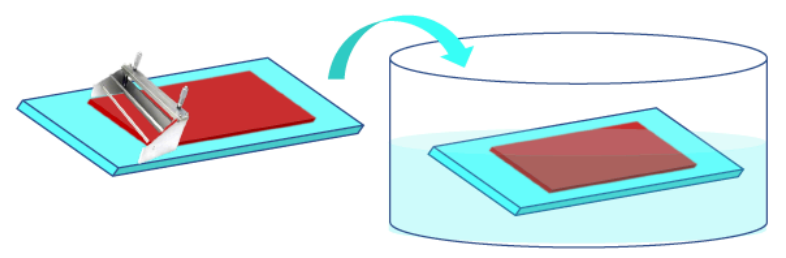

Casting and

immersion in water

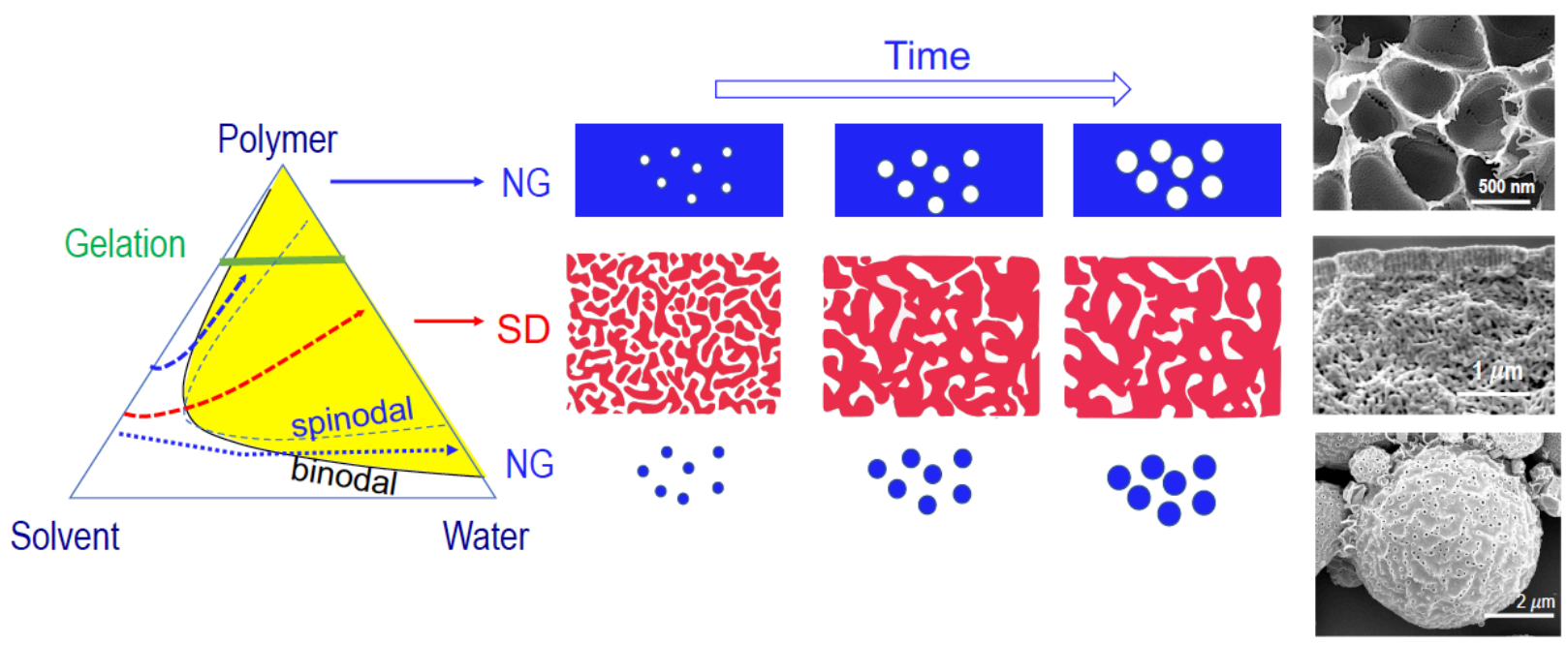

Figure 3. Solution casting and immersion in water and the consequent phase separation process. Depending on the water-solvent exchange path, the phase separation may follow the mechanisms of spinodal decomposition (SD) or nucleation and growth (NG). At low polymer concentration, NG leads to the formation of particles, while at high concentration, polymer-lean nuclei may form a honeycomb network of cavities. Asymmetric membranes with a gradient of pores from the top to the bottom and a highly ordered isoporous layer on the top can be favored by SD. A gelation interrupts the phase separation, immobilizing the developing morphology and trapping it in a nonequilibrium thermodynamic state. (Images adapted from ref. [5, 64-66])

The membrane formation by SNIPS follows in part the phase inversion mechanism widely used for commercial membranes[5,64], summarized in Figure 3 . When the polymer solution is cast and immersed in water, the solvent-non-solvent exchange will bring the system to a thermodynamic instability and lead to a progressive separation in a polymer-lean and a polymerconcentrated phases. The initial polymer concentration in solution is the main parameter to decide if the result will be a self-standing film (high concentration), useful for membrane application, or dispersed isolated particles (low concentration). There are two classical mechanisms of phase separation: spinodal decomposition (SD) and nucleation and growth (NG). SD dominates if the solvent-non-solvent exchange is fast and the thermodynamic conditions rapidly deteriorate to favor the separation, "quenching" the system into the instable region of the phase diagram. Even a relatively slow exchange can favor SD if the paths into the two-phases area of the phase diagram does not cross a metastable condition (red line in Figure 3). On the other hand, NG is the favored mechanism if the system goes through a metastable condition for some time, before fully separating in two-phases. SD starts with a local and continues concentration oscillation. The polymer concentration difference between the two developing phases smoothly increases with the time. If the initial polymer concentration is high enough, a highly viscous and continuous polymer matrix is formed and the separation is kinetically trapped. In the case of NG polymer lean (or polymer concentrated, depending on the total polymer content in the system) nuclei are formed. 
The polymer concentration in the nuclei remains practically constant as the separation proceeds; the nuclei grow by in size, by transport of polymer and some solvent molecules from the continuous phase. Homopolymer and block copolymer solutions follow these mechanisms of "macrophase" separation.

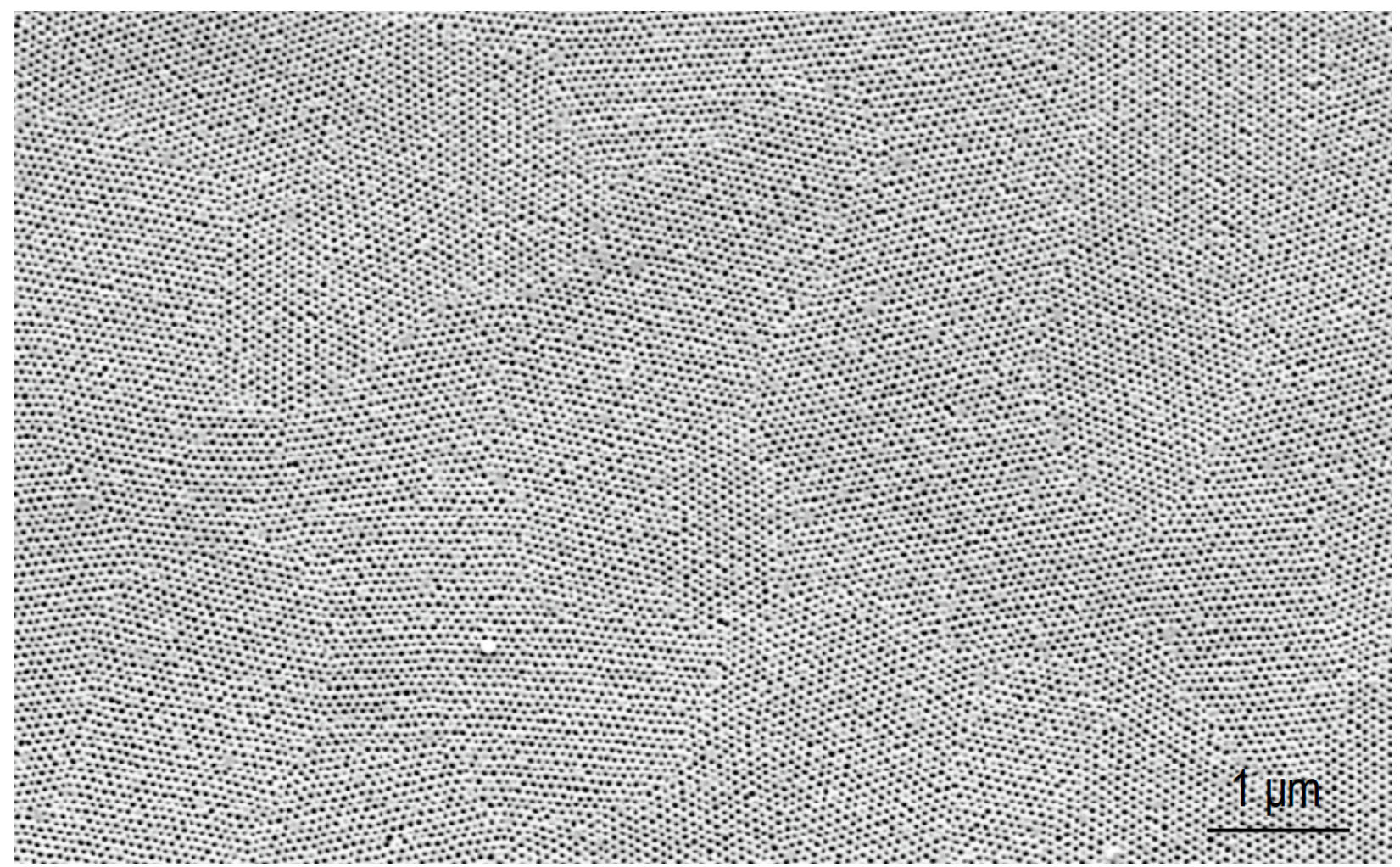

Figure 4. SEM image of the surface of a PS- $b$-P4VP isoporous membrane, prepared by SNIPS.[64, 67]

What really differs when block copolymers are used is that, in addition to the SD or NG "macrophase" separation, they have the ability to self-assembly in solution in the nanoscale. In diluted solutions, they assemble into individual micelles, rods or vesicles, as in Figure 2. If the concentration is high enough, these separated unities will themselves arrange in a supramolecular assembly, forming an ordered network. This micelle assembly highly influences the final membrane morphology. The first evidences for that were proposed and demonstrated by Nunes et al.[64] Details on the exact micelle assembly and a complete understanding of all the stages leading to the final pore formation are still a topic of discussion and investigation. A comprehensive description of the pore formation is complex and might need to consider additional aspects, such as surface phenomena and their influence on the late stages of the pore formation.[5]

Figure 3 shows 3 different block copolymer structures, which are tuned by navigating the phase diagram with different paths. The middle one is the most commonly reported asymmetric isoporous membrane, mainly following the SD phase separation mechanism. Highly interconnected pores are formed, with a gradient of growing pore sizes from the top to the bottom of the membrane. Only the top layer $(<500 \mathrm{~nm})$ is isoporous (see surface image in Figure 4) with dominant influence of the block copolymer self-assembly. If the initial copolymer concentration is low, a continuous film will not be formed, but the NG mechanism can promote the formation of 
porous particles with internal order.[65] Here again the block copolymer self-assembly also play an important role and the order is influenced by the minimization of the energy in a confined state. The system depicted on the top right of Figure 3 was most recently reported and will be discussed at the end of this chapter.[66] In this case a metastable stage develops with the formation of polymer-lean nuclei. The morphology is immobilized, as the nuclei grow surrounded by a concentrated polymer matrix. The contribution of the block copolymer self-assembly in this case is the formation of a highly ordered isoporous morphology in the walls interconnecting the micrometer-sized cavities.

Influence of the order in solution. The self-assembly in the casting solution of block copolymer isoporous membranes has been confirmed in detailed by small-angle x-ray scattering static[68-70] and time-resolved experiments, pioneered by KAUST and Cornell groups.[71] Experiments have been later conducted by different groups. Even if in detail the interpretations might differ, the proposed relevance of the self-assembly in solution has been confirmed by all groups.[70, 72-75] By comparing a PS- $b$-P4VP diblock and the corresponding triblock copolymer with isoprene as the third block, it was observed that hexagonal or body centered cubic self-assembly in solution, as in Figure 5, were correlated to the same kind of pore arrangement in the membrane pore distribution.[68] Therefore not only the presence of order in solution is essential, but its kind.
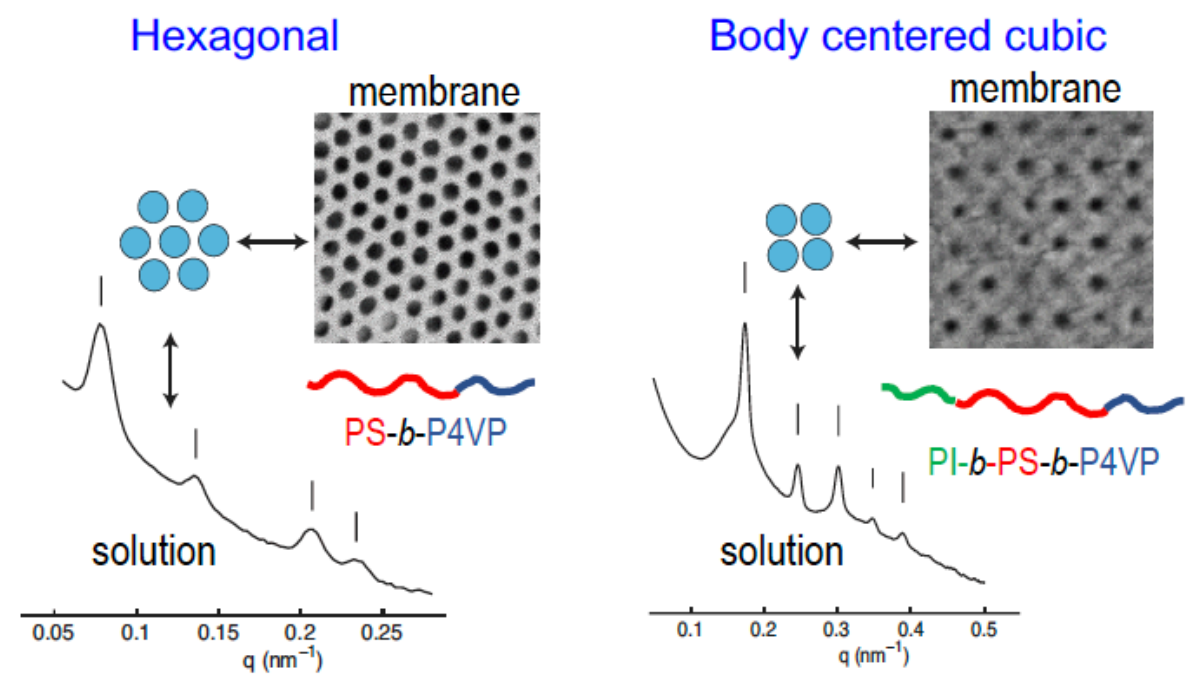

Figure 5. Correlation between order in solution, confirmed by SAXS and the surface membrane pore morphology, exemplified for the diblock PS- $b$-P4VP and triblock PI- $b$-PS- $b$-P4VP copolymers. (Adapted from ref. [68]) 
Polystyrene-b-poly(4-vinyl pyridine) (PS-b-P4VP)

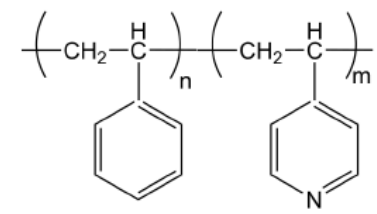

Polyisoprene-b-polystyrene-b-poly(4-vinyl pyridine)

(PI-b-PS-b-P4VP)

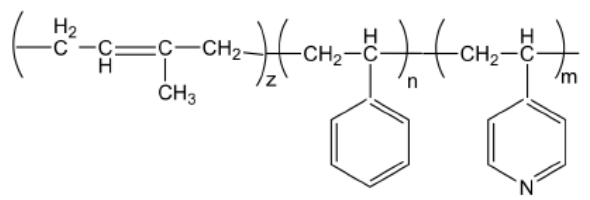

Polystyrene-b-poly(acrylic acid)

(PS-b-PAA)

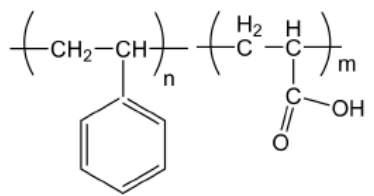

Scheme 2. Block copolymers commonly used for SNIPS membrane preparation

Complexing agents. Having in mind the relevance of the self-assembly in solution, and the need to stabilize it, salts were added in the casting solution of PS- $b$-P4VP. The reproducibility and order could be effectively improved.[64, 67] The kind of cation and its ability to complex with P4VP strongly influence the final regularity of the membrane, $\mathrm{Cu}^{2+}$ being the most effective among those tested, being also the one with the highest metal-pyridine complex stability constant.[67] The complexation by H-bond can stabilize the self-assembly in solution as well.[76] It has been demonstrated that excessively strong $\mathrm{H}$-bond interactions, as provided by mellitic acid, which has 6 carboxylic acid groups per molecule, or 1,3,5-tris(4'carboxyl[1,1'biphenyl]-4-yl) benzene, with 3 carboxylic groups, can crosslink into a lamellar morphology, unsuitable for membranes. Surprisingly, the rigid monofunctionalized 9-anthracenemethanol molecules were the most effective additives in a series of complexing agents. This indicated that increasing the micelles rigidity is of primary relevance. A low deformability helps to reach the isoporosity. A combination of electrostatic forces and $\mathrm{H}$-bond interactions is provided by the addition of ionic liquids to a block copolymer solution. By changing the ionic liquid composition, the membrane morphology can be guided or completely modified.[77] By adding protic ionic liquids to a PS- $b$-P4VP solution, a lamellar morphology was achieved, while with aprotic analogs, with less stronger interactions, membranes with circular pores were favored. Figure 6 summarize the effect of different additives and solvents. 


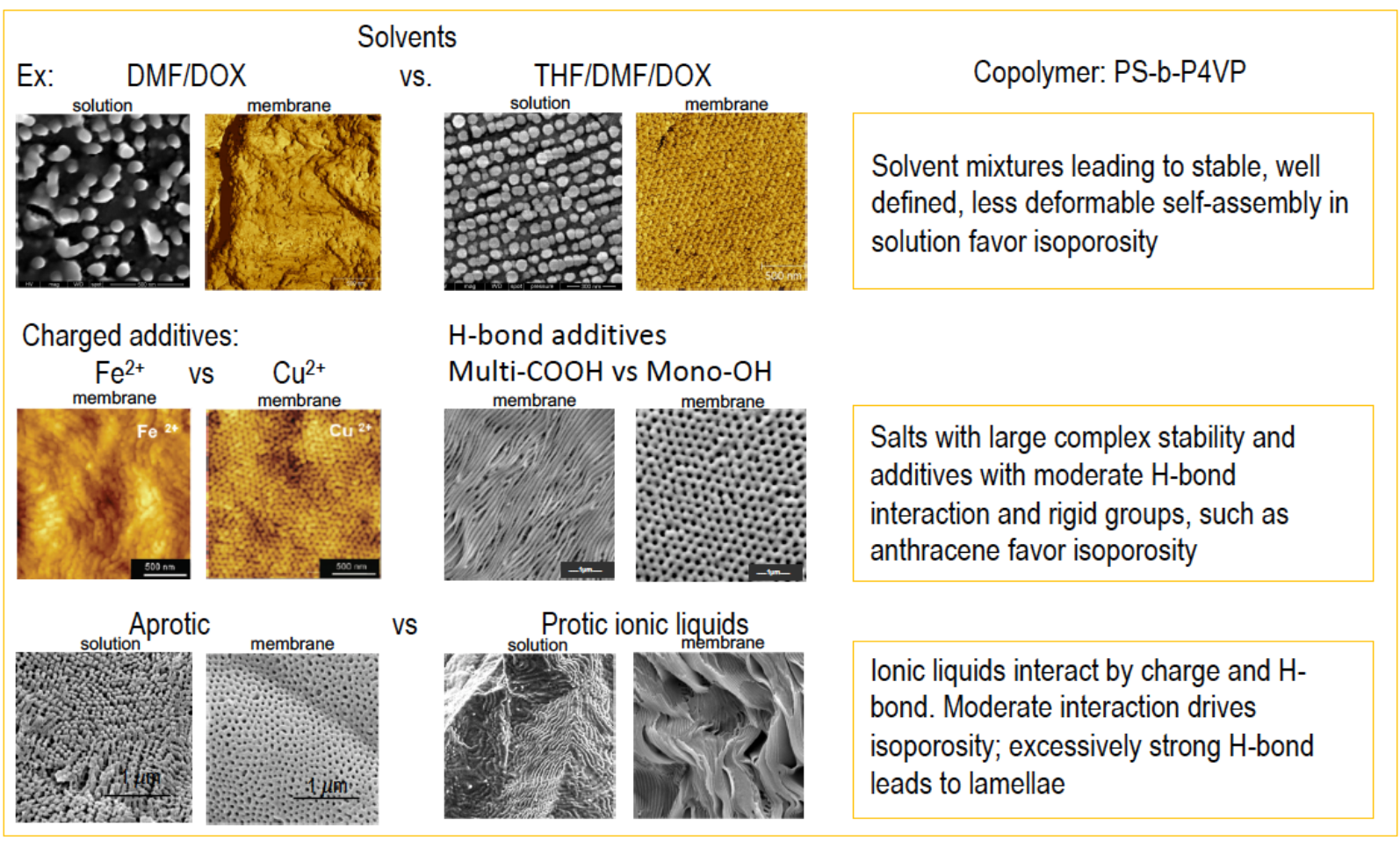

Figure 6. Influence of solvent and additives on the SNIPS block copolymer membranes morphology. (Images adapted from ref. [67, 76-78])

Solvent optimization. Complexing agents are not essential for obtaining good isoporous membranes. They facilitate the self-assembly, stabilize the morphology. But by choosing the right solvent mixture the final morphology can be optimized as well. DMF/THF luckily worked for the first reported isoporous PS- $b$-P4VP membrane, but this is not the most convenient solvent mixture for this system. Nunes et al.[78] early demonstrated that by adding dioxane to the mixture a much more regular membrane morphology could be reproduced. This could be explained by correlating it with the order observed in the binary and ternary DMF/THF/dioxane solutions, visualized by cryo-scanning electron microscopy[71, 78] and SAXS/GISAXS.[69, 71] A semi-empirical method for identifying convenient solvent mixtures for block copolymers leading to isoporous membranes was proposed by Sutisna et al.[79] They plotted a ratio of Flory-Huggins interaction parameters as a function of the blocks volume ratios for a number of investigated systems that were successful or unsuccessful in leading to isopores, as shown in Figure 7. This an excellent guide for optimization, particularly when new block copolymer compositions start to be tested, but it is just the first step. Once the best solvent mixture has been identified, the adjustment of the polymer concentration is the next essential step to guarantee a stable self-assembly. 

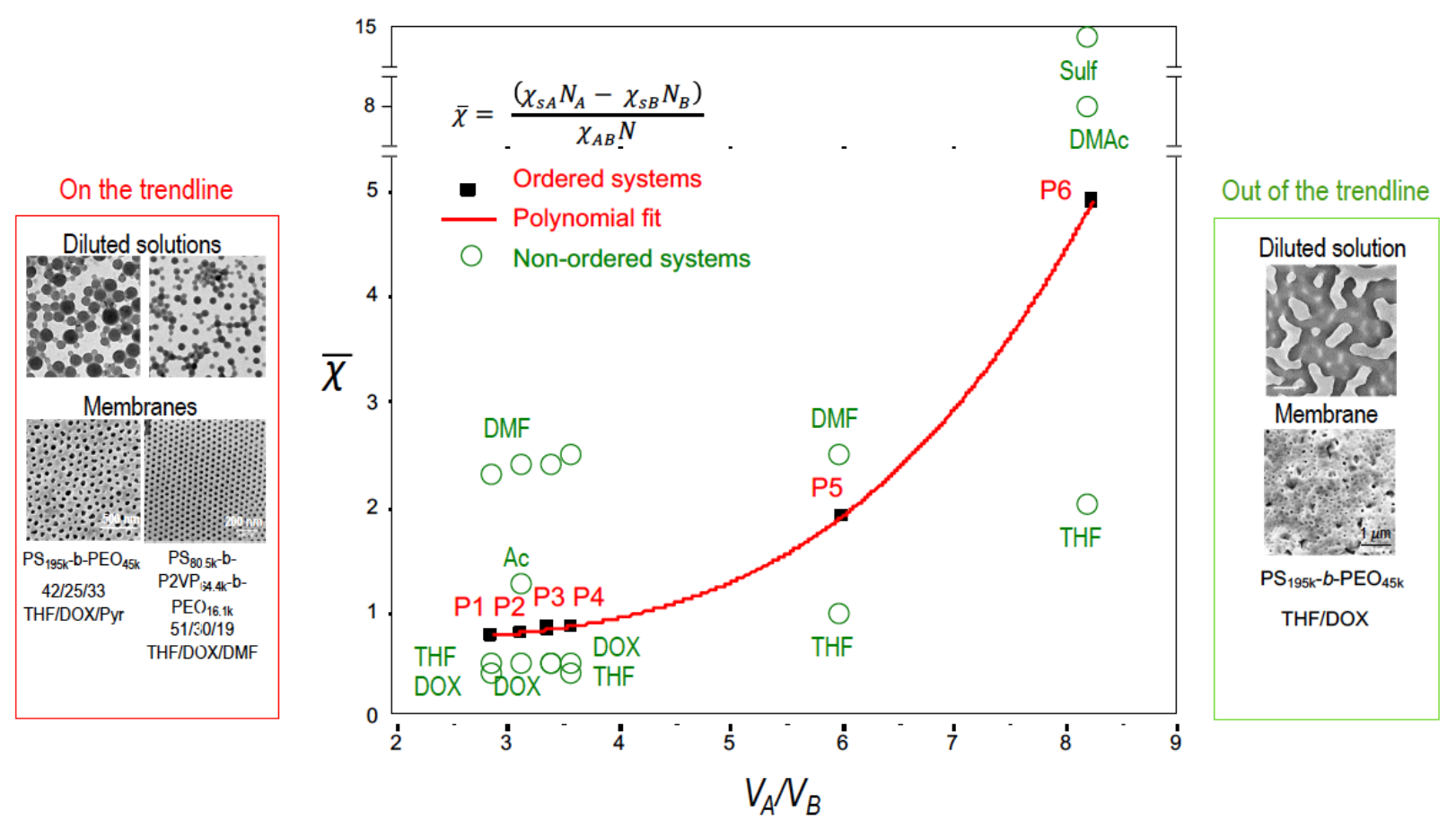

Figure 7. Trendline guide for solvent mixtures screening in the membrane preparation. The red curve represents the compositions that led to isoporous morphology, while the green dots are relative to non-uniform. The TEM microscopy of micelles formed in the diluted solutions and the corresponding membranes illustrate the correlation of the trendline and the obtained morphologies. (Adapted from ref. [79])

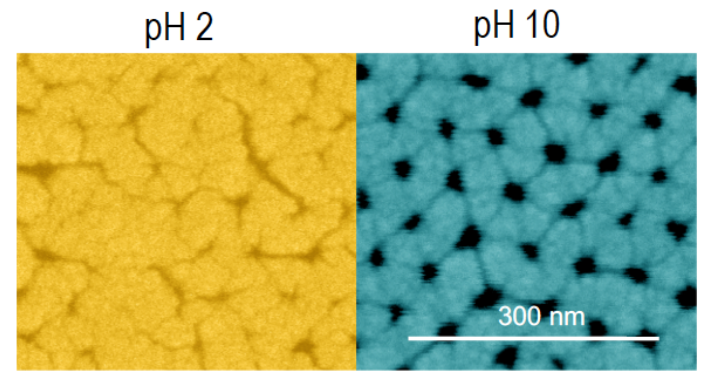

Figure 8. Cryo-SEM of the surface of a PS- $b$-P4VP previously immersed in buffer solutions with different $\mathrm{pH}$ values. (Adapted from ref. [67])

Beyond size: separation by charge and stimuli response. Besides the excellent size-sieving ability of PS- $b$-P4VP membranes, separation can be tune also by the $\mathrm{pH}$. The membranes are stimuliresponsive.[67] At low $\mathrm{pH}$, the pyridine groups are protonated, becoming positively charged. The hydrophilic segments, which constitute the pore wall, stretch reducing the pore size, as shown in Figure 8. The process is reversible. The pore reduction or enlargement can be tuned by controlling the $\mathrm{pH}$. In addition, the surface charge might contribute to the separation. This is particularly useful in the case of proteins, which can be preferentially positive or negative depending also on $\mathrm{pH}$. Polyacrylic acid (PAA) blocks respond to $\mathrm{pH}$ in an opposite way to pyridine. Isoporous membranes and particles based on PS- $b$-PAA have their pores reduced and the surface turning positive at high 
$\mathrm{pH} .[65,80,81]$ Their capacity of binding metals also changes with $\mathrm{pH}$ and have been explored for selective ion transport.[82] The response to light has been demonstrated for block copolymer membranes with anthracene pending groups.[83]

Tailoring pore size. Most membranes prepared by SNIPS have pores in the ultrafiltration range with pore sizes above $10 \mathrm{~nm}$. Preparing nanofiltration membranes by SNIPS is challenging. The self-assembly in the melt and in solution is highly dependent on the interaction parameter between blocks, $\chi_{\mathrm{AB}}$, and on the ratio between the degrees of polymerization of each block relative to the total one. This has a direct implication on the resulting morphology of the SNIPS membranes. The other parameter that is at least as important is the copolymer total molecular weight. The dimensions of micelles, cylinders and other assembled unities in solution depend on molecular weight and the pore sizes of the resulting membranes are also expected to vary. This has been clearly shown for polystyrene-[84]-poly(ethylene oxide) (PS- $b$-PEO) and PI- $b$-PS- $b$-P4VP membranes[85, 86] (Scheme 2) and later reported also for mixtures of PS- $b$-P4VP [87] of different molecular weights (Figure 9). However, a hypothetical strategy of reducing the molecular weight enough to obtain nanofiltration membranes with well-defined round pores of size far below $10 \mathrm{~nm}$ is restricted by the fact that the block segregations is a function of the interaction between block and also of the polymerization degree, N. This can be more easily seen in order-disorder plots for deblock copolymer melts. Below a certain polymerization degree, $\chi_{\mathrm{AB}} \mathrm{N}<0.5$, the system is disordered and probably would not lead to an isoporous membrane formation. As mentioned, when the membrane pores are constituted by $\mathrm{P} 4 \mathrm{VP}$ or PAA, a change in $\mathrm{pH}$ can cause a drastic change of pore size down to $1-3.5 \mathrm{~nm}$, but this is also associated with a strong undesirable permeation decrease even below $1 \mathrm{~L} \mathrm{~m}^{-2} \mathrm{~h}^{-1} \mathrm{bar}^{-1}$. Gu et al.[88] added glycerol to the casting solution of isoporous membranes. This increased the pore size and by controlling the $\mathrm{pH}$, the blocks on the wall expanded but did not close the pores completely. About $5 \mathrm{~nm}$ were left open for a permeation of $15 \mathrm{~L} \mathrm{~m}^{-2} \mathrm{~h}^{-1}$ bar $^{-1}$. The most effective demonstrated strategy to prepare isoporous nanofiltration membranes so far has been blending PS- $b$-P4VP copolymers with PS- $b$-PAA of much lower molecular weight. A high density of pores as small as $1.5 \mathrm{~nm}$, rejection of $600 \mathrm{~g} / \mathrm{mol}$, and a high permeation of $43215 \mathrm{~L} \mathrm{~m}^{-2} \mathrm{~h}^{-1} \mathrm{bar}^{-1}$ could then be obtained. A simulation by dissipative particle dynamics, showing how different copolymer ratios in the blend affect the self-assembly in the casting solution is shown in Figure 10. Other approaches for reducing the pore sizes are based on post modification[5] by atomic layer deposition[69], electroless gold deposition[89].

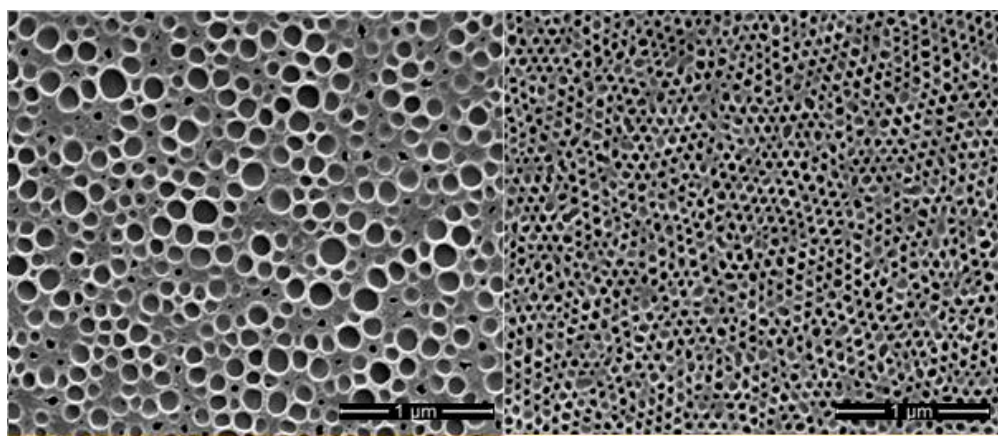

(a)

(b)

Figure 9. Block copolymer membranes prepared from $22 \mathrm{wt} \%$ (a) $\mathrm{PS}_{227 \mathrm{~K}}-b-\mathrm{PEO}_{61 \mathrm{~K}}$ (b) $\mathrm{PS}_{138 \mathrm{~K}}-b-\mathrm{PEO}_{18 \mathrm{~K}}$ solutions in THF/DMAc/sulfolane.(Adapted from ref. [85]) 


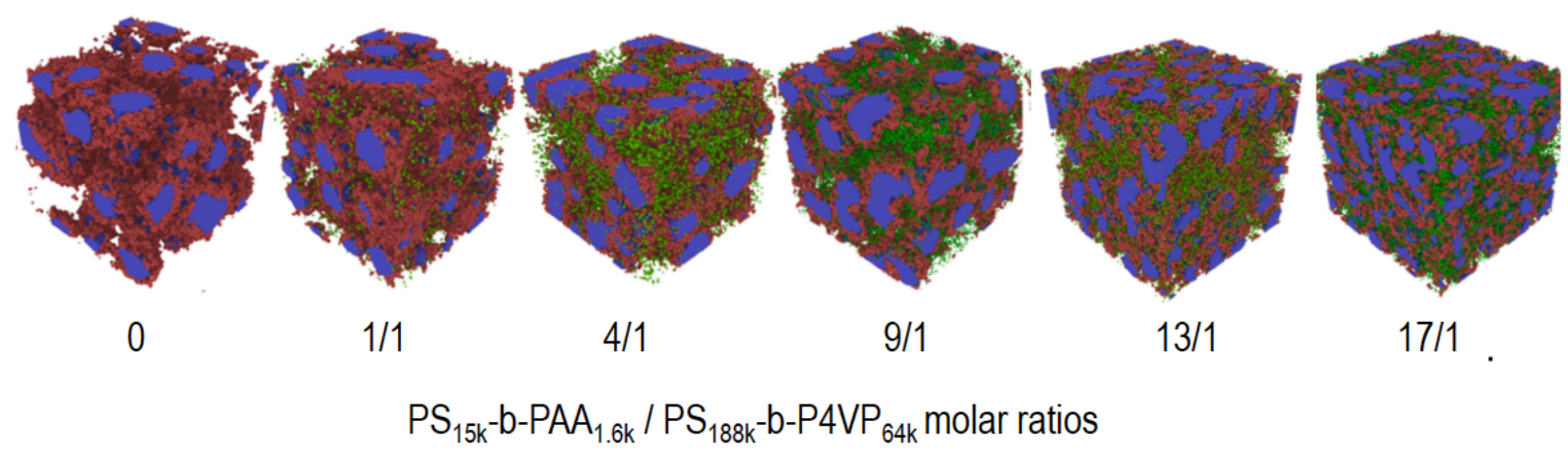

Figure 10. Dissipative particle dynamics simulation of the self-assembly of blends with different molar ratios of PS- $b$-PAA/PS- $b$-P4VP in solution. The small domains lead to the formation of membranes with pore sizes around $1.7 \mathrm{~nm}$. (Adapted from ref. [90, 91])

From lab to technical manufacture. Block copolymer membranes based on PS- $b$-P4VP or similar di- or triblock copolymers have been progressing since the first reports.[63, 64] Their manufacture has been demonstrated as flat-sheet or hollow fiber [92-96] in the lab. The scale-up of flat-sheet block copolymer membranes in semi-technical machines have been demonstrated at KAUST[97], being a topic of a "seed fund" initiative in 2010. As for most commercial polymeric membranes, a non-woven is commonly used to increase the mechanical stability of the membranes and allow the preparation in continues machines. The industrial preparation of block copolymer membranes is now being conducted by Terapore (https://teraporetech.com).

Different chemistries and additives. PS- $b$-P4VP and PI- $b$-PS- $b$-P4VP copolymer membranes have been the most explored ones and have been serving as a platform for further functionalization and modifications targeting different applications. By incorporating additives such as silver [98], gold [92], $\mathrm{TiO}_{2}$ [99], metal-organic frameworks [100] and carbon nanotubes [101], functions such as biofouling resistance, catalytic activity, drug delivery, and sensing have been added to the membranes. The copolymers with pyridine or PEO blocks are however just a few of innumerous others with great potential for membranes. Probably the big chances for block copolymer membranes still to be explored are the exploration of new chemistries and functionalizations. One important aspect is the potential advantage that would bring the substitution of the polystyrene block by other segments more frequently used for stable membranes. Examples could be polysulfone, polyacrylonitrile or fluorinated backbones. Polysulfone block copolymers were prepared

Xie et al. $[39,102,103]$ with the purpose of membrane preparation. In the first report copolymers with azide groups for the postfunctionalization by click chemistry [39] were prepared. More recently postfunctionalization by click chemistry has been applied to PS- $b$-P4VP.[104] In a different approach a combination of polycondensation and reversible addition-fragmentation chain transfer (RAFT) copolymerization was applied to prepare poly(t-butyl acrylate)-b-polysulfone- $b$ poly(t-butyl acrylate) [102]. The hydrolysis of the acrylate lead to the formation of poly(acrylic acid) blocks. The chelation with salts guided the formation of an ordered structure.[103]

Anionic copolymerization is one of the most effective methods to obtain macromolecules with minimum polydispersity and well-defined blocks. Different copolymer systems (Scheme 3) were recently explored by the Nunes's group in collaboration with Hadjichristidis' group at 
KAUST. The first of them is poly(styrene-b-tert-butoxystyrene-b-styrene) [105] and clearly demonstrates the relevance of the pore functionalization. This copolymer offers a large density of hydroxy groups, which are effective hydrogen bonds promoters. Small H-bond promoters such as pyridine and imidazole were used as additives. The nanopores were small enough to retain $97 \%$ of PEG molecules with $10 \mathrm{~kg} / \mathrm{mol}$ molecular weight and $42 \%$ of PEG with $3 \mathrm{~kg} / \mathrm{mol}$, but rejects only $32 \%$ cytrochrom c $(12.4 \mathrm{~kg} / \mathrm{mol})$ and $25 \%$ of lysozyme $(14.3 \mathrm{~kg} / \mathrm{mol})$. The Stokes radii of these compound are similar, around $1.5-2.8 \mathrm{~nm}$. PEG $3 \mathrm{~kg} / \mathrm{mol}$ is the lowest one. The permeant dimensions are similar to the pore size. While permeating, a strong contact with the pore walls is promoted. Probably the $\mathrm{OH}$ groups on the pore walls preferentially facilitate the transport of the proteins with the right balance of reversible $\mathrm{H}$-bonds formation.

Another recent example is a membrane prepared from polystyrene- $b$-polybutadiene- $b$ polystyrene (SBS) prepared also by anionic polymerization.[106] SBS is commercially available in large scale and low cost with a block ratio different than that used for the membrane preparation. This is important to mention because it indicates that the cost of block copolymers can be considerably reduced if produced in the technical scale and should not be seen as an obstacle for membrane manufacture. The approach applied to the SBS membrane took advantage of the butadiene double bond, reacting it with a thiol molecule. Hydrophilic channels could then be obtained. The strategy could be in principle applied to any copolymer with double bonds and at the same time to other thiol molecules, working as a platform for tuning functionalization.

Finally, membranes were prepared from poly(styrene- $b-\gamma$-benzyl-L-glutamate) casting solutions.[107] The peptide block has a helicoidal conformation, guiding the formation of nanochannels and providing H-bonds.

Polystyrene- $b$-polybutadiene- $b$-polystyrene

(SBS)

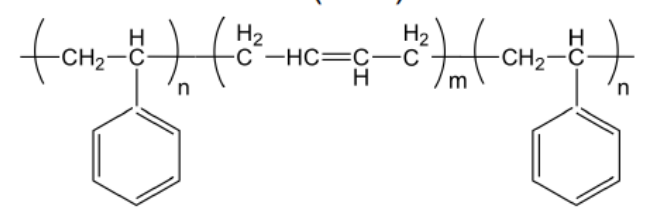

Polystyrene- $b$-poly(hydroxyl styrene)- $b$-polystyrene (PS-b-PSOH-b-PS)

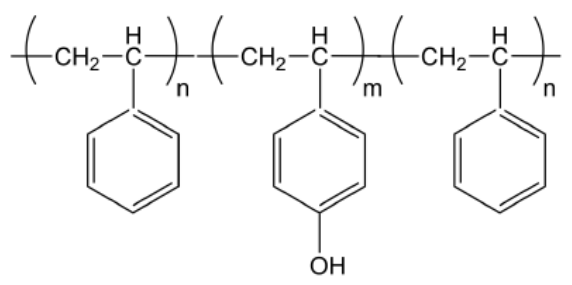

Polystyrene- $b$-benzyl-L-glutamate)

(PS-b-PBGL)

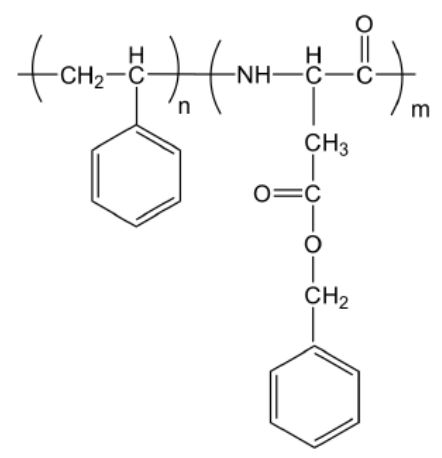

Scheme 3. Block copolymers recently used for SNIPS membranes.[105-107]

\section{Advantages, drawbacks, and perspectives}

The main advantages of block copolymers for membrane fabrication are the precise pore morphology, much better defined than regular homopolymers can provide, high porosity and rich possibilities of functionalization. The SNIPS method leads to isoporous selective layers in asymmetric membranes practically in one stage, without etching. The potential to effectively 
enable separations for instance of biological systems in a much more effective way than done by other classes of membranes. Drawbacks for immediate commercialization at this moment are the still the relatively high cost of the copolymers optimized for isoporous membranes and the fact that the morphology is more sensitive to minor variations of molecular weight than homopolymer membranes. The first step in the scale-up should, therefore, be that of the copolymer synthesis Block copolymers such as styrene-butadiene-styrene are available in large scale and this should be feasible. Other aspects of scale-up do not differ from homopolymer membranes and strategies such as the use of non-woven supports in continuous machines have been long being demonstrated.[97]

In order to extend the membrane application, copolymers with blocks more stable than polystyrene in terms of temperature and solvent resistance. Initiatives Blocks with compositions analogous to those currently used for homopolymer membranes would give more robust systems. However, the methods of polymerization should also guarantee low polydispersity and welldefined blocks. Crosslinking strategies would be important to secure solvent resistance. Crosslinking examples have been reported [108-110] for membrane systems requiring block etching for pore formation and for microgels.[111] Pyrolysis of block copolymer films [112, 113] could be extended to membranes.

Most porous films prepared by SNIPS are asymmetric membranes, only the thin $(<500 \mathrm{~nm})$ top layer being isoporous. Fully isoporous 3D hierarchical structures $[66,114]$ have been now demonstrated, mimicking the complex morphology of biological systems with the perspective of applications also for separations and selective transport. In this case solutions of copolymers with both hydrophobic blocks, such as polystyrene-b-poly(t-butyl acrylate) (PS- $b$-PtBA), were prepared in DMF solvent mixtures. A phase separation by nucleation and growth takes place with the polymer-lean nuclei developing to cavities of micrometer size. A high density of isopores with $15 \mathrm{~nm}$ diameter are formed, interconnecting all cavities, as shown in Figure 11. The hydrophobicity can be controlled by hydrolysis of PS- $b$-PtBA (Scheme 4). This morphology has potential application for separations, as well as for catalysis and as biomedical scaffolds. Analogous systems are being now investigated and tested for different applications.

Table 1 summarizes the main achievements in the last decade on the SNIPS process. The combination of block copolymers and classical polymer solution thermodynamic is an emerging field with broad opportunities for developing membranes for aqueous and solvent-based separations with strict size-sieving selectivity, allied to a variety of possible functionalizations for separations stimulated by chemical affinity. Stimuli-responsive gates could extend the application as dynamic systems in the biomedical sector and sensors industry. 


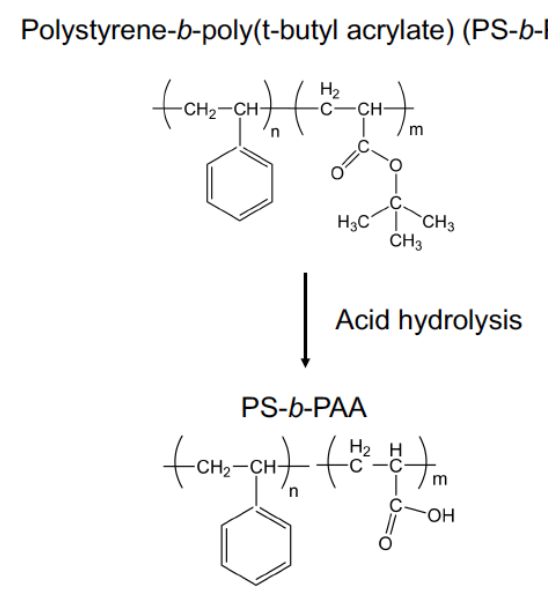

Scheme 4. Block copolymer for 3D hierarchical isotropic structures: PS- $b$-PtBA and its hydrolysis to PS-b-PAA for carboxylation and hydrophilization.[66]

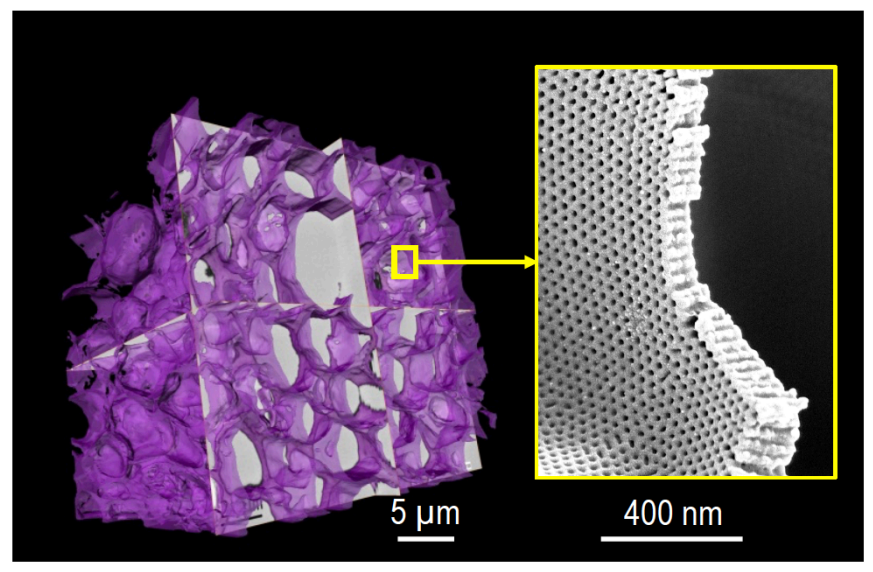

Figure 11.3D Hierarchical porous structure prepared by block copolymer self-assembly and nucleation and growth: serial block face SEM image on the left, showing the cross-section of a porous isotropic film with micrometer-size cavities and a high SEM magnification of the wall between cavities. (Adapted from ref. [66]) 
Table 1. Milestones in block copolymer membranes prepared by self-assembly and non-solvent induced phase separation (SNIPS).

\begin{tabular}{|c|c|c|}
\hline Date & Milestone & Reference \\
\hline 2007 & First isoporous SNIPS membranes (PS- $b$-P4VP in DMF/THF casting solution) & [63] \\
\hline 2010 & $\begin{array}{l}\text { Reproducible PS- } b \text {-P4VP membrane with added copper acetate } \\
\text { Report on the influence of micelle formation in solution on the membrane } \\
\text { morphology; use of SAXS, FIB and cryo TEM and cryo SEM to demonstrate it }\end{array}$ & [64] \\
\hline 2011 & $\begin{array}{l}\text { pH responsive isoporous membranes (pore size switching from } 20 \text { to } 1 \mathrm{~nm} \text { ) } \\
\text { Block copolymer membranes prepared on non-woven to improve stability and } \\
\text { facilitate the scale-up in machines ("seed fund" initiative at KAUST) }\end{array}$ & [67] \\
\hline 2011 & $\begin{array}{l}\text { Proposition of more efficient solvent mixtures, including dioxane for better } \\
\text { membranes reproducibility without added salts }\end{array}$ & [78] \\
\hline 2011 & Isoporous triblock membranes based on PI- $b$-PS- $b$-P4VP & [115] \\
\hline 2012 & $\begin{array}{l}\text { SAXS demonstration that the self-assembly order in solution correlates with the } \\
\text { final membrane morphology }\end{array}$ & [68] \\
\hline 2013 & Block copolymer membranes fabrication in machines & [97] \\
\hline 2013 & First isoporous hollow fiber membranes & {$[92,95,97]$} \\
\hline 2013 & Catalytic isoporous membranes with gold nanoparticles & [92] \\
\hline 2013 & $\begin{array}{l}\text { Influence of complexing additives with strong } \mathrm{H} \text {-bond formation and the } \\
\text { relevance of micelle rigidity; rheological investigation and correlation with } \\
\text { morphology }\end{array}$ & [76] \\
\hline 2013 & $\begin{array}{l}\text { Use of dissipative particle dynamic combined to SAXS to demonstrate the } \\
\text { isoporous membrane formation }\end{array}$ & {$[116]$} \\
\hline 2013 & Spinout TeraPore founded to manufacture block copolymer membranes & Teraporetech.com \\
\hline 2014 & $\begin{array}{l}\text { First dual layer hollow fiber membranes with homopolymer as internal layer and } \\
\text { isoporous block copolymer outer layer }\end{array}$ & [93] \\
\hline 2014 & $\begin{array}{l}\text { PS- } b \text {-PEO isoporous membranes and the influence of molecular weight on the } \\
\text { pore size }\end{array}$ & [85] \\
\hline 2014 & $\begin{array}{l}\text { RAFT copolymerization applied to the preparation of isoporous triblock } \\
\text { membranes }\end{array}$ & [117] \\
\hline 2014 & Pore tuning between 3 and $20 \mathrm{~nm}$ with electroless gold deposition & [89] \\
\hline 2014 & Anfiro start-up (anfiro.com) & \\
\hline 2015 & Time-resolved GISAXS applied to follow the membrane formation & [71] \\
\hline 2015 & $\begin{array}{l}\text { Asymmetric isoporous membranes used as template for inorganic porous } \\
\text { materials }\end{array}$ & {$[88,118]$} \\
\hline 2015 & $\begin{array}{l}\text { Ionic liquids used to drive the block copolymer self-assembly and the membrane } \\
\text { morphology }\end{array}$ & [77] \\
\hline 2015 & $\begin{array}{l}\text { Membranes based on polysulfone copolymers with azide groups for further click } \\
\text { chemistry postmodification }\end{array}$ & [39] \\
\hline 2015 & $\begin{array}{l}\text { Used of mixtures of PS- } b \text {-P4VP of different molecular weights to tune the pore } \\
\text { size down to } 20 \mathrm{~nm}\end{array}$ & [87] \\
\hline 2015 & Use of glycerol and $\mathrm{pH}$ protonation to reduce the pore size to $5 \mathrm{~nm}$ & [88] \\
\hline 2015 & $\begin{array}{l}\text { Blends of PS- } b \text {-P4VP and PS- } b \text {-PAA copolymers to obtain membranes with pore } \\
\text { size in the range of nanofiltration (ca. } 1.5 \mathrm{~nm} \text { ) }\end{array}$ & {$[90,91]$} \\
\hline 2016 & Photoresponsive membranes based on anthracene blocks & [83] \\
\hline 2016 & $\begin{array}{l}\text { Block copolymer membranes without polystyrene block: polysulfone and acrylic } \\
\text { acid blocks }\end{array}$ & {$[102,103]$} \\
\hline 2016 & $\begin{array}{l}\text { Semi-empirical trendline solvent selection proposed for block copolymer } \\
\text { membranes }\end{array}$ & [79] \\
\hline 2018 & $\begin{array}{l}\text { Membranes prepared from diverse block compositions (e. g. PS- } b \text {-PSOH- } b \text {-PS, } \\
\text { thiol-modified SBS) }\end{array}$ & {$[105,106]$} \\
\hline 2018 & 3D isotropic isoporous films prepared from block copolymers & {$[66,114]$} \\
\hline 2018 & Membranes prepared from copolymers with polypeptide blocks & [107] \\
\hline
\end{tabular}




\section{Acknowledgements}

The Nunes's work on block copolymer membranes has been supported by the King Abdullah University of Science and Technology (KAUST). This chapter is a summary of the research on block copolymer membranes with selected examples from different groups in the field. The author thanks all co-authors and collaborators of the Nanostructured Polymeric Lab, Klaus Peinemann, Nikos Hadjichristidis, Victor Calo, their co-workers and the core lab at KAUST. Special thanks also to Detlef Smilgies and Uli Wiesner's group at Cornell and the synchrotron scientists at the LNLS in Brazil, and DESY, Germany.

\section{References}

[1] F.S. Bates, G.H. Fredrickson, Block copolymers designer soft materials, Physics today, 52 (1999) 32.

[2] F.S. Bates, M.A. Hillmyer, T.P. Lodge, C.M. Bates, K.T. Delaney, G.H. Fredrickson, Multiblock Polymers: Panacea or Pandora's Box?, Science, 434 (2012) 440.

[3] C.M. Bates, F.S. Bates, 50th Anniversary Perspective: Block Polymers-Pure Potential, Macromolecules, 50 (2016) 3-22.

[4] J.N. Israelachvili, Intermolecular and Surface Forces, (2011).

[5] S.P. Nunes, Block Copolymer Membranes for Aqueous Solution Applications, Macromolecules, 49 (2016) 2905-2916.

[6] I.P. Blume, Ingo, Composite membrane, method of preparation and use, in, MTR, US, 1987.

[7] M.L.N. Sforça, S. P.; Peinemann, K. V., Composite nanofiltration membranes prepared by in situ polycondensation of amines in a poly(ethylene oxide-b-amide) layer Journal of Membrane Science, 135 (1997) 179-186.

[8] S.P.S. Nunes, M. L.; Peinemann, K. V., Dense hydrophilic composite membranes for ultrafiltration, Journal of Membrane Science, 106 (1995) 49-56.

[9] K.W.B. Boeddeker, G.; Pingel, H., Pervaporation of isomeric butanols, Journal of Membrane Science, 54 (1990) 1-12.

[10] S. Shishatskiy, J.R. Pauls, S.P. Nunes, K.-V. Peinemann, Quaternary ammonium membrane materials for CO2 separation, Journal of Membrane Science, 359 (2010) 44-53.

[11] A. Car, C. Stropnik, W. Yave, K.-V. Peinemann, PEG modified poly(amide-b-ethylene oxide) membranes for $\mathrm{CO} 2$ separation, Journal of Membrane Science, 307 (2008) 88-95.

[12] T.C. Merkel, H. Lin, X. Wei, R. Baker, Power plant post-combustion carbon dioxide capture: An opportunity for membranes, Journal of Membrane Science, 359 (2010) 126-139.

[13] R.W. Baker, B.T. Low, Gas Separation Membrane Materials: A Perspective, Macromolecules, 47 (2014) 6999-7013.

[14] W. Fam, J. Mansouri, H. Li, V. Chen, Improving CO 2 separation performance of thin film composite hollow fiber with Pebax ${ }^{\circledR} 1657 /$ ionic liquid gel membranes, Journal of Membrane Science, 537 (2017) 54-68.

[15] T. Khosravi, M. Omidkhah, S. Kaliaguine, D. Rodrigue, Amine-functionalized CuBTC/poly(ether-b-amide-6) (Pebax ${ }^{\circledR}$ 
$\mathrm{MH}$ 1657) mixed matrix membranes for $\mathrm{CO} 2$

/CH4

separation, The Canadian Journal of Chemical Engineering, 95 (2017) 2024-2033.

[16] P.D. Sutrisna, J. Hou, M.Y. Zulkifli, H. Li, Y. Zhang, W. Liang, Deanna M. D'Alessandro, V. Chen, Surface functionalized UiO-66/Pebax-based ultrathin composite hollow fiber gas separation membranes, Journal of Materials Chemistry A, 6 (2018) 918-931.

[17] W. Yave, A. Car, S.S. Funari, S.P. Nunes, K.-V. Peinemann, CO2-Philic Polymer Membrane with Extremely High Separation Performance, Macromolecules, 43 (2010) 326-333.

[18] X. Ren, J. Ren, M. Deng, Poly(amide-6-b-ethylene oxide) membranes for sour gas separation, Separation and Purification Technology, 89 (2012) 1-8.

[19] K.W. Boeddeker, Pervaporation of phenols, in, Germany, 1989.

[20] K.W.B. Boddeker, G.; Bode, E., Pervaporation of low volatility aromatics from water, Journal of Membrane Science, 53 (1990) 143-158.

[21] M.L. Sforça, I.V.P. Yoshida, C.P. Borges, S.P. Nunes, Hybrid membranes based on $\mathrm{SiO}$ /polyether-b-polyamide: Morphology and applications, Journal of Applied Polymer Science, 82 (2001) 178-185.

[22] J. Aburabie, K.-V. Peinemann, Crosslinked poly(ether block amide) composite membranes for organic solvent nanofiltration applications, Journal of Membrane Science, 523 (2017) 264272.

[23] C. Cuevas, D. Kim, K.P. Katuri, P. Saikaly, S.P. Nunes, Electrochemically active polymeric hollow fibers based on poly(ether- $b$-amide)/carbon nanotubes, Journal of Membrane Science, 545 (2018) 323-328.

[24] G.M. Geise, B.D. Freeman, D.R. Paul, Characterization of a sulfonated pentablock copolymer for desalination applications, Polymer, 51 (2010) 5815-5822.

[25] Z. Thong, G. Han, Y. Cui, J. Gao, T.S. Chung, S.Y. Chan, S. Wei, Novel nanofiltration membranes consisting of a sulfonated pentablock copolymer rejection layer for heavy metal removal, Environ Sci Technol, 48 (2014) 13880-13887.

[26] P. Marchetti, A.G. Livingston, Predictive membrane transport models for Organic Solvent Nanofiltration: How complex do we need to be?, Journal of Membrane Science, 476 (2015) 530553.

[27] J. Zuo, G.M. Shi, S. Wei, T.S. Chung, The development of novel Nexar block copolymer/Ultem composite membranes for C2-C4 alcohols dehydration via pervaporation, ACS Appl Mater Interfaces, 6 (2014) 13874-13883.

[28] G.M. Shi, J. Zuo, S.H. Tang, S. Wei, T.S. Chung, Layer-by-layer (LbL) polyelectrolyte membrane with Nexar ${ }^{\mathrm{TM}}$ polymer as a polyanion for pervaporation dehydration of ethanol, Separation and Purification Technology, 140 (2015) 13-22.

[29] P.V. Truong, S. Shingleton, M. Kammoun, R.L. Black, M. Charendoff, C. Willis, H. Ardebili, G.E. Stein, Structure and Properties of Sulfonated Pentablock Terpolymer Films as a Function of WetDry Cycles, Macromolecules, 51 (2018) 2203-2215.

[30] F.H.V.H. Akhtar, Villalobos, Luis Francisco; Shevate, Rahul; Kumar, Mahendra; Nunes, Suzana Pereira; Schwingenschloegl; Peinemann, Klaus-Viktor, Highways for water molecules: Interplay between nanostructure and water vapor transport in block copolymer membranes, (2018).

[31] F. Huang, T.D. Largier, W. Zheng, C.J. Cornelius, Pentablock copolymer morphology dependent transport and its impact upon film swelling, proton conductivity, hydrogen fuel cell 
operation, vanadium flow battery function, and electroactive actuator performance, Journal of Membrane Science, 545 (2018) 1-10.

[32] A. Taeger, C. Vogel, D. Lehmann, D. Jehnichen, H. Komber, J. Meier-Haack, N.A. Ochoa, S.P. Nunes, K.V. Peinemann, Ion exchange membranes derived from sulfonated polyaramides, Reactive and Functional Polymers, 57 (2003) 77-92.

[33] Y. Álvarez-Gallego, B. Ruffmann, V. Silva, H. Silva, A.E. Lozano, J.G. de la Campa, S.P. Nunes, J. de Abajo, Sulfonated polynaphthalimides with benzimidazole pendant groups, Polymer, 49 (2008) 3875-3883.

[34] D.W. Shin, M.D. Guiver, Y.M. Lee, Hydrocarbon-Based Polymer Electrolyte Membranes: Importance of Morphology on Ion Transport and Membrane Stability, Chem Rev, 117 (2017) 4759-4805.

[35] K. Zhang, S. Gong, B. Zhao, Y. Liu, N.A. Qaisrani, L. Li, F. Zhang, G. He, Bent-twisted block copolymer anion exchange membrane with improved conductivity, Journal of Membrane Science, 550 (2018) 59-71.

[36] B.D. McCloskey, H.B. Park, H. Ju, B.W. Rowe, D.J. Miller, B.D. Freeman, A bioinspired foulingresistant surface modification for water purification membranes, Journal of Membrane Science, 413-414 (2012) 82-90.

[37] H.-C. Yang, J. Luo, Y. Lv, P. Shen, Z.-K. Xu, Surface engineering of polymer membranes via mussel-inspired chemistry, Journal of Membrane Science, 483 (2015) 42-59.

[38] N.L. Le, M. Ulbricht, S.P. Nunes, How Do Polyethylene Glycol and Poly(sulfobetaine) Hydrogel Layers on Ultrafiltration Membranes Minimize Fouling and Stay Stable in Cleaning Chemicals?, Industrial \& Engineering Chemistry Research, 56 (2017) 6785-6795.

[39] Y. Xie, R. Tayouo, S.P. Nunes, Low fouling polysulfone ultrafiltration membrane via click chemistry, Journal of Applied Polymer Science, 132 (2015).

[40] J. Meyer, M. Ulbricht, Poly(ethylene oxide)- block -poly(methyl methacrylate) diblock copolymers as functional additive for poly(vinylidene fluoride) ultrafiltration membranes with tailored separation performance, Journal of Membrane Science, 545 (2018) 301-311.

[41] S.P.P. Nunes, K. V., Ultrafiltration membranes from PVDF/PMMA blends Journal of Membrane Science, 73 (1992) 25-35.

[42] C.J. Weinman, N. Gunari, S. Krishnan, R. Dong, M.Y. Paik, K.E. Sohn, G.C. Walker, E.J. Kramer, D.A. Fischer, C.K. Ober, Protein adsorption resistance of anti-biofouling block copolymers containing amphiphilic side chains, Soft Matter, 6 (2010).

[43] B.H. Tan, H. Hussain, K.C. Chaw, G.H. Dickinson, C.S. Gudipati, W.R. Birch, S.L.M. Teo, C. He, Y. Liu, T.P. Davis, Barnacle repellent nanostructured surfaces formed by the self-assembly of amphiphilic block copolymers, Polym. Chem., 1 (2010) 276-279.

[44] M. Lejars, A. Margaillan, C. Bressy, Fouling release coatings: a nontoxic alternative to biocidal antifouling coatings, Chem Rev, 112 (2012) 4347-4390.

[45] S.W. Krishnan, Nick; Ober, Christopher; Finlay, John A.; Callow, Maureen; Callow, James; Hexemer, Alexander; Sohn, Karen; Kramer, Edward; Fischer, Daniel, Comparison of the fouling release properties of hydrophobic fluorinated and hydrophilic PEGylated block copolymer surfaces, Biomacromolecules, 7 (2006) 1449-1462.

[46] P.H.H. Duong, K. Daumann, P.-Y. Hong, M. Ulbricht, S.P. Nunes, Interfacial Polymerization of Zwitterionic Building Blocks for High-Flux Nanofiltration Membranes, Langmuir, (2018). 
[47] J.A. Walker, K.J. Robinson, C. Munro, T. Gengenbach, D.A. Muller, P.R. Young, L.H.L. Lua, S.R. Corrie, Antibody-Binding, Antifouling Surface Coatings Based on Recombinant Expression of Zwitterionic EK Peptides, Langmuir, (2018).

[48] M. Piatkovsky, H. Acar, A.B. Marciel, M. Tirrell, M. Herzberg, A zwitterionic block-copolymer, based on glutamic acid and lysine, reduces the biofouling of UF and RO membranes, Journal of Membrane Science, 549 (2018) 507-514.

[49] J.S. Lee, A. Hirao, S. Nakahama, Polymerization of monomers containing functional silyl groups. 5. Synthesis of new porous membranes with functional groups, Macromolecules, 21 (1988) 274-276.

[50] J.S. Lee, A. Hirao, S. Nakahama, Polymerization of monomers containing functional silyl groups. 7. Porous membranes with controlled microstructures, Macromolecules, 22 (1989) 26022606.

[51] S.Y. Chen, Y. Huang, R.C.C. Tsiang, Ozonolysis efficiency of PS-b-PI block copolymers for forming nanoporous polystyrene, Journal of Polymer Science Part A: Polymer Chemistry, 46 (2008) 1964-1973.

[52] M. Park, C. Harrison, P.M. Chaikin, R.A. Register, D.H. Adamson, Block copolymer lithography: periodic arrays of 1011 holes in 1 square centimeter, Science, 276 (1997) 14011404.

[53] S. Park, J.Y. Wang, B. Kim, J. Xu, T.P. Russell, A simple route to highly oriented and ordered nanoporous block copolymer templates, ACS nano, 2 (2008) 766-772.

[54] T. Thurn-Albrecht, R. Steiner, J. DeRouchey, C.M. Stafford, E. Huang, M. Bal, M. Tuominen, C.J. Hawker, T.P. Russell, Nanoscopic templates from oriented block copolymer films, Advanced Materials, 12 (2000) 787-791.

[55] W.A. Phillip, M.A. Hillmyer, E. Cussler, Cylinder orientation mechanism in block copolymer thin films upon solvent evaporation, Macromolecules, 43 (2010) 7763-7770.

[56] L. Chen, W.A. Phillip, E. Cussler, M.A. Hillmyer, Robust nanoporous membranes templated by a doubly reactive block copolymer, Journal of the American Chemical Society, 129 (2007) 13786-13787.

[57] E.A. Jackson, M.A. Hillmyer, Nanoporous Membranes Derived from Block Copolymers: From Drug Delivery to Water Filtration, ACS nano, 4 (2010) 3548-3553.

[58] M. Seo, D. Moll, C. Silvis, A. Roy, S. Querelle, M.A. Hillmyer, Interfacial Polymerization of Reactive Block Polymers for the Preparation of Composite Ultrafiltration Membranes, Industrial \& Engineering Chemistry Research, 53 (2014) 18575-18579.

[59] M. Seo, M.A. Hillmyer, Reticulated Nanoporous Polymers by Controlled PolymerizationInduced Microphase Separation, Science, 336 (2012) 1422-1425.

[60] D. Ndaya, R. Bosire, L. Mahajan, S. Huh, R. Kasi, Synthesis of ordered, functional, robust nanoporous membranes from liquid crystalline brush-like triblock copolymers, Polymer Chemistry, 9 (2018) 1404-1411.

[61] L.D. McIntosh, M.W. Schulze, M.T. Irwin, M.A. Hillmyer, T.P. Lodge, Evolution of Morphology, Modulus, and Conductivity in Polymer Electrolytes Prepared via Polymerization-Induced Phase Separation, Macromolecules, 48 (2015) 1418-1428.

[62] S.A. Saba, M.P. Mousavi, P. Bühlmann, M.A. Hillmyer, Hierarchically Porous Polymer Monoliths by Combining Controlled Macro-and Microphase Separation, Journal of the American Chemical Society, 137 (2015) 8896-8899. 
[63] K.V. Peinemann, V. Abetz, P.F.W. Simon, Asymmetric superstructure formed in a block copolymer via phase separation, Nature Materials, 6 (2007) 992-996.

[64] S.P. Nunes, R. Sougrat, B. Hooghan, D.H. Anjum, A.R. Behzad, L. Zhao, N. Pradeep, I. Pinnau, U. Vainio, K.V. Peinemann, Ultraporous films with uniform nanochannels by block copolymer micelles assembly, Macromolecules, 43 (2010) 8079-8085.

[65] H. Yu, X. Qiu, S.P. Nunes, K.V. Peinemann, Biomimetic block copolymer particles with gated nanopores and ultrahigh protein sorption capacity, Nat Commun, 5 (2014) 4110.

[66] S.M. Chisca, Valentina; Sougrat, Rachid; Behzad, Ali; Nunes, Suzana P., Artificial 3D hierarchical and isotropic porous polymeric materials, 4 (2018) eaat0713.

[67] S.P. Nunes, A.R. Behzad, B. Hooghan, R. Sougrat, M. Karunakaran, N. Pradeep, U. Vainio, K.V. Peinemann, Switchable pH-Responsive Polymeric Membranes Prepared via Block Copolymer Micelle Assembly, ACS nano, 5 (2011) 3516-3522.

[68] R.M. Dorin, D.S. Marques, H. Sai, U. Vainio, W.A. Phillip, K.V. Peinemann, S.P. Nunes, U. Wiesner, Solution Small-Angle X-ray Scattering as a Screening and Predictive Tool in the Fabrication of Asymmetric Block Copolymer Membranes, ACS Macro Letters, 1 (2012) 614-617.

[69] D.S. Marques, U. Vainio, N.M. Chaparro, V.M. Calo, A.R. Bezahd, J.W. Pitera, K.-V. Peinemann, S.P. Nunes, Self-assembly in casting solutions of block copolymer membranes, Soft Matter, 9 (2013) 5557-5564.

[70] V. Musteata, B. Sutisna, G. Polymeropoulos, A. Avgeropoulos, F. Meneau, K.-V. Peinemann, N. Hadjichristidis, S.P. Nunes, Self-assembly of polystyrene- b -poly(2-vinylpyridine)- b poly(ethylene oxide) triblock terpolymers, European Polymer Journal, 100 (2018) 121-131.

[71] D.S. Marques, R.M. Dorin, U. Wiesner, D.-M. Smilgies, A.R. Behzad, U. Vainio, K.-V. Peinemann, S.P. Nunes, Time-resolved GISAXS and cryo-microscopy characterization of block copolymer membrane formation, Polymer, 55 (2014) 1327-1332.

[72] C. Stegelmeier, A. Exner, S. Hauschild, V. Filiz, J. Perlich, S.V. Roth, V. Abetz, S. Förster, Evaporation-induced block copolymer self-assembly into membranes studied by in situ synchrotron SAXS, Macromolecules, 48 (2015) 1524-1530.

[73] H. Yu, X. Qiu, N. Moreno, Z. Ma, V.M. Calo, S.P. Nunes, K.V. Peinemann, Self-Assembled Asymmetric Block Copolymer Membranes: Bridging the Gap from Ultra-to Nanofiltration, Angewandte Chemie International Edition, 54 (2015) 13937-13941.

[74] S. Dami, C. Abetz, B. Fischer, M. Radjabian, P. Georgopanos, V. Abetz, A correlation between structural features of an amphiphilic diblock copolymer in solution and the structure of the porous surface in an integral asymmetric membrane, Polymer, 126 (2017) 376-385.

[75] Y. Gu, R.M. Dorin, K.W. Tan, D.-M. Smilgies, U. Wiesner, In situ study of evaporation-induced surface structure evolution in asymmetric triblock terpolymer membranes, Macromolecules, 49 (2016) 4195-4201.

[76] P. Madhavan, K.V. Peinemann, S.P. Nunes, Complexation-tailored morphology of asymmetric block copolymer membranes, ACS Appl Mater Interfaces, 5 (2013) 7152-7159.

[77] P. Madhavan, R. Sougrat, A.R. Behzad, K.-V. Peinemann, S.P. Nunes, lonic liquids as selfassembly guide for the formation of nanostructured block copolymer membranes, Journal of Membrane Science, 492 (2015) 568-577.

[78] S.P. Nunes, M. Karunakaran, N. Pradeep, A.R. Behzad, B. Hooghan, R. Sougrat, H. He, K.V. Peinemann, From micelle supramolecular assemblies in selective solvents to isoporous membranes, Langmuir, 27 (2011) 10184-10190. 
[79] B. Sutisna, G. Polymeropoulos, V. Musteata, K.-V. Peinemann, A. Avgeropoulos, D.-M. Smilgies, N. Hadjichristidis, S.P. Nunes, Design of block copolymer membranes using segregation strength trend lines, Molecular Systems Design \& Engineering, 1 (2016) 278-289.

[80] X. Qiu, H. Yu, M. Karunakaran, N. Pradeep, S.P. Nunes, K.-V. Peinemann, Selective separation of similarly sized proteins with tunable nanoporous block copolymer membranes, ACS Nano, 7 (2012) 768-776.

[81] J.L. Weidman, R.A. Mulvenna, B.W. Boudouris, W.A. Phillip, Nanostructured membranes from triblock polymer precursors as high capacity copper adsorbents, Langmuir, 31 (2015) 1111311123.

[82] S. Qu, T. Dilenschneider, W.A. Phillip, Preparation of Chemically-Tailored Copolymer Membranes with Tunable Ion Transport Properties, ACS applied materials \& interfaces, 7 (2015) 19746-19754.

[83] P. Madhavan, B. Sutisna, R. Sougrat, S.P. Nunes, Photoresponsive nanostructured membranes, RSC Advances, 6 (2016) 75594-75601.

[84] L. Guo, Z. Zhong, Y. Wang, Atomic Layer Deposition on Block Copolymer Membranes with Gyroidal Nanopores Toward Periodically Nanostructured Vapor Sensors: Nanotubes versus Nanorods, Advanced Materials Interfaces, 3 (2016).

[85] M. Karunakaran, S.P. Nunes, X. Qiu, H. Yu, K.-V. Peinemann, Isoporous PS-b-PEO ultrafiltration membranes via self-assembly and water-induced phase separation, Journal of Membrane Science, 453 (2014) 471-477.

[86] R.M. Dorin, W.A. Phillip, H. Sai, J. Werner, M. Elimelech, U. Wiesner, Designing block copolymer architectures for targeted membrane performance, Polymer, 55 (2014) 347-353.

[87] M. Radjabian, V. Abetz, Tailored Pore Sizes in Integral Asymmetric Membranes Formed by Blends of Block Copolymers, Advanced Materials, 27 (2015) 352-355.

[88] Y. Gu, U. Wiesner, Tailoring Pore Size of Graded Mesoporous Block Copolymer Membranes: Moving from Ultrafiltration toward Nanofiltration, Macromolecules, 48 (2015) 6153-6159.

[89] H. Yu, X. Qiu, S.P. Nunes, K.V. Peinemann, Self-Assembled Isoporous Block Copolymer Membranes with Tuned Pore Sizes, Angewandte Chemie, 126 (2014) 10236-10240.

[90] H. Yu, X. Qiu, N. Moreno, Z. Ma, V.M. Calo, S.P. Nunes, K.V. Peinemann, Self-Assembled Asymmetric Block Copolymer Membranes: Bridging the Gap from Ultra-to Nanofiltration, Angewandte Chemie International Edition, 54 (2015) 13937-13941.

[91] N. Moreno, S.P. Nunes, K.-V. Peinemann, V.M. Calo, Topology and Shape Control for Assemblies of Block Copolymer Blends in Solution, Macromolecules, (2015).

[92] R. Hilke, N. Pradeep, P. Madhavan, U. Vainio, A.R. Behzad, R. Sougrat, S.P. Nunes, K.-V. Peinemann, Block copolymer hollow fiber membranes with catalytic activity and pH-response, ACS applied materials \& interfaces, 5 (2013) 7001-7006.

[93] R. Hilke, N. Pradeep, A.R. Behzad, S.P. Nunes, K.-V. Peinemann, Block copolymer/homopolymer dual-layer hollow fiber membranes, Journal of Membrane Science, 472 (2014) 39-44.

[94] K. Sankhala, J. Koll, M. Radjabian, U.A. Handge, V. Abetz, A Pathway to Fabricate Hollow Fiber Membranes with Isoporous Inner Surface, Advanced Materials Interfaces, 4 (2017).

[95] M. Radjabian, J. Koll, K. Buhr, U.A. Handge, V. Abetz, Hollow Fibre Spinning of Block Copolymers: Influence of Spinning Conditions on Morphological Properties, Polymer, (2013). 
[96] M. Radjabian, J. Koll, K. Buhr, U. Vainio, C. Abetz, U.A. Handge, V. Abetz, Tailoring the morphology of self-assembled block copolymer hollow fiber membranes, Polymer, 55 (2014) 2986-2997.

[97] S.P. Nunes, A.R. Behzad, K.-V. Peinemann, Self-assembled block copolymer membranes: From basic research to large-scale manufacturing, Journal of Materials Research, 28 (2013) 26612665.

[98] P. Madhavan, P.Y. Hong, R. Sougrat, S.P. Nunes, Silver-enhanced block copolymer membranes with biocidal activity, ACS Appl Mater Interfaces, 6 (2014) 18497-18501.

[99] Y. Gu, R.M. Dorin, U. Wiesner, Asymmetric organic-inorganic hybrid membrane formation via block copolymer-nanoparticle co-assembly, Nano letters, 13 (2013) 5323-5328.

[100] H. Yu, X. Qiu, P. Neelakanda, L. Deng, N.M. Khashab, S.P. Nunes, K.V. Peinemann, Hollow ZIF-8 Nanoworms from Block Copolymer Templates, Sci Rep, 5 (2015) 15275.

[101] R. Shevate, M.A. Haque, F.H. Akhtar, L.F. Villalobos, T. Wu, K.V. Peinemann, Embedding 1D Conducting Channels into 3D Isoporous Polymer Films for High-Performance Humidity Sensing, Angewandte Chemie International Edition, (2018).

[102] Y. Xie, N. Moreno, V.M. Calo, H. Cheng, P.-Y. Hong, R. Sougrat, A.R. Behzad, R. Tayouo, S.P. Nunes, Synthesis of highly porous poly(tert-butyl acrylate)-b-polysulfone-b-poly(tert-butyl acrylate) asymmetric membranes, Polymer Chemistry, 7 (2016) 3076-3089.

[103] Y. Xie, B. Sutisna, S.P. Nunes, Membranes prepared by self-assembly and chelation assisted phase inversion, Chem Commun (Camb), 53 (2017) 6609-6612.

[104] C. Höhme, V. Filiz, C. Abetz, P. Georgopanos, N. Scharnagl, V. Abetz, Postfunctionalization of Nanoporous Block Copolymer Membranes via Click Reaction on Polydopamine for Liquid Phase Separation, ACS Applied Nano Materials, 1 (2018) 3124-3136.

[105] B. Sutisna, G. Polymeropoulos, E. Mygiakis, V. Musteata, K.V. Peinemann, D.M. Smilgies, N. Hadjichristidis, S.P. Nunes, Artificial membranes with selective nanochannels for protein transport, Polymer Chemistry, 7 (2016) 6189-6201.

[106] B. Sutisna, G. Polymeropoulos, V. Musteata, R. Sougrat, D.M. Smilgies, K.V. Peinemann, N. Hadjichristidis, S.P. Nunes, Functionalized Nanochannels from Self-Assembled and Photomodified Poly(Styrene-b-Butadiene-b-Styrene), Small, 14 (2018) e1701885.

[107] B.B. Sutisna, P.; Musteata, V.; Smilgies, D.; Peinemann, K.-V.; Hadjichristidis, N.; Nunes, S. P., Self-assembled membranes with feather-like and lamellar morphologies containing $\alpha$-helical polypeptides, Macromolecules, (2018).

[108] M. Seo, Robust Mesoporous Polymers Derived from Cross-Linked Block Polymer Precursors, in: Submicron Porous Materials, Springer, 2017, pp. 53-79.

[109] T. Vidil, N. Hampu, M.A. Hillmyer, Nanoporous Thermosets with Percolating Pores from Block Polymers Chemically Fixed above the Order-Disorder Transition, ACS Central Science, 3 (2017) 1114-1120.

[110] S.A. Chopade, J.G. Au, Z. Li, P.W. Schmidt, M.A. Hillmyer, T.P. Lodge, Robust Polymer Electrolyte Membranes with High Ambient-Temperature Lithium-Ion Conductivity via Polymerization-Induced Microphase Separation, ACS Applied Materials \& Interfaces, 9 (2017) 14561-14565.

[111] X. Wang, J.L. Davis, B.M. Aden, B.S. Lokitz, S.M. Kilbey, Versatile Synthesis of AmineReactive Microgels by Self-Assembly of Azlactone-Containing Block Copolymers, Macromolecules, 51 (2018) 3691-3701. 
[112] Q. Zhang, F. Matsuoka, H.S. Suh, P.A. Beaucage, S. Xiong, D.M. Smilgies, K.W. Tan, J.G. Werner, P.F. Nealey, U.B. Wiesner, Pathways to Mesoporous Resin/Carbon Thin Films with Alternating Gyroid Morphology, ACS Nano, 12 (2018) 347-358.

[113] T. Kowalewski, N.V. Tsarevsky, K. Matyjaszewski, Nanostructured carbon arrays from block copolymers of polyacrylonitrile, Journal of the American Chemical Society, 124 (2002) 1063210633.

[114] V.-E. Musteata, S. Chisca, F. Meneau, D.-M. Smilgies, S.P. Nunes, Carboxyl-functionalized nanochannels based on block copolymer hierarchical structures, Faraday Discussions, (2018).

[115] W.A. Phillip, R. Mika Dorin, J. Werner, E.M.V. Hoek, U. Wiesner, M. Elimelech, Tuning Structure and Properties of Graded Triblock Terpolymer-Based Mesoporous and Hybrid Films, Nano Letters, (2011).

[116] D.S. Marques, Micellar Self-Assembly of Block Copolymers for Fabrication of Nanostructured Membranes, in, King Abdullah University of Science and Technology, 2013.

[117] R.A. Mulvenna, J.L. Weidman, B. Jing, J.A. Pople, Y. Zhu, B.W. Boudouris, W.A. Phillip, Tunable nanoporous membranes with chemically-tailored pore walls from triblock polymer templates, Journal of Membrane Science, 470 (2014) 246-256.

[118] Y. Gu, J.G. Werner, R.M. Dorin, S.W. Robbins, U. Wiesner, Graded porous inorganic materials derived from self-assembled block copolymer templates, Nanoscale, 7 (2015) 58265834. 